\title{
Multidimensional and Interactive Assessment Model of Large-Scale Infrastructure Project and Its Demonstration Based on Double Utility
}

\author{
Wu Gao, ${ }^{1,2}$ Kairong Hong, ${ }^{1}$ and Bin $\operatorname{Pan}^{3}$ \\ ${ }^{1}$ Business School, Central South University, Changsha 410083, China \\ ${ }^{2}$ Department of City Management, Hunan City University, Yiyang 413000, China \\ ${ }^{3}$ Business School, Wenzhou University, Wenzhou 325399, China \\ Correspondence should be addressed to Wu Gao; gw740620@sina.com
}

Received 26 November 2015; Revised 5 June 2016; Accepted 19 June 2016

Academic Editor: Yakov Strelniker

Copyright ( $2016 \mathrm{Wu}$ Gao et al. This is an open access article distributed under the Creative Commons Attribution License, which permits unrestricted use, distribution, and reproduction in any medium, provided the original work is properly cited.

\begin{abstract}
This paper evaluates the project risks with a multidimensional and interactive model from multiagent and utility combination, which takes subjective psychological negative utility into account rather than only focusing on the thinking pattern of objective value loss. Firstly, it analyzes the bodies' heterogeneous preference and their game behavior using game theory application methods. Secondly, it builds multidimensional and interactive evaluation model of large-scale infrastructure project from many dimensions, such as risk rate, objective utility, and subjective utility. It reflects different values and behavior strategy interdynamic factor in the design of risk utility function. Lastly, it deduces process and approaches of multidimensional and interactive evaluation by typical project. In addition, it tests model parameter with regression analysis. The research of this paper broadens the dimension of project risk evaluation and provides comprehensive and balanced reference for the measure of project risk utility and a better basis for project risk control.
\end{abstract}

\section{Introduction}

Large-scale infrastructure project, which profoundly affects social economy and ecological environment, is hugely invested with a strong public property, concerning multiinterests and participants. Its main body is in the complex dynamic game in the process of project construction and operation. Large-scale infrastructure project risk refers to overall value of negative deviation (loss) brought by uncertainties of complex dynamic environment or body itself. It has subjective and objective values [1]. Objective value refers to the sum of economic, social, and environmental ecology value, which is measured by cash flow, while subjective value is a sense of happiness and satisfaction that is gained by relevant subject, which is measured by other forms of conversion. According to Expected Utility Function Theory made by Neumann and Morgenstern [2], the goal of rational behavior decision-making subject is the pursuit of utility maximization, rather than the maximum profit; therefore, "utility" indicator can be used as evaluation and measurement of main body material and nonmaterial loss brought by large-scale infrastructure project risk. Risk loss is the utility loss of subject, which is more suitable than traditional cash flow indicator [3]. Risk evaluation dimensions and methods of existing literature on large-scale infrastructure project risk are two-dimensional, three-dimensional, and multidimensional evaluation methods [4]. Two-dimensional evaluation method considers two key factors: the probability of risk events and economic losses. The risk size is the probability of occurrence and function of economic loss. Three-dimensional evaluation not only considers the risk events probability and damage degree, but also takes the body feel $[5,6]$ into account, such as "emotional evaluation model of project risk subject" proposed by Loewenstein et al. [7] and Slovic et al. [8] and "expectation effect evaluation model of project risk subject" proposed by $\mathrm{Lu}$ and Yan [9]. Undoubtedly, three-dimensional evaluation is more scientific than two-dimensional evaluation for it conforms more to 
complex features of the risk of major infrastructure projects. Based on three-dimensional evaluation, the multidimensional evaluation method joins factors such as risk control, scalability, and transferability. But it still has certain limitation for it only considers the subjective factors of single evaluation subject without considering multiple subject value of different risk preference and multiple subject project behavioral strategy interaction factors when evaluating the risk [10]. The assignment methods about the impact of project risk value in existing literature mainly include the fuzzy evaluation method and gray evaluation method. The design of the index weight mainly uses AHP, ANP, and entropy weight methods. The existing literature combines game theory with project risk for the analysis of project risk control; for example, Xiang and $\mathrm{Lu}$ [11] thought that the rational project should consider the risk of others when assessing the risk of their own for the main risks were interdependent; Li et al. [12] pointed out that the project between the main bodies had bargaining game in the process of risk control, but papers that introduce the game theory into the project risk evaluation are few [13]. In conclusion, large-scale infrastructure project risk assessment is not an enclosed behavior evaluation subject but must consider game decision results of other related subjects [14]. The project risk evaluation should fully embody and reflect risk of multiple projects subject values and different understanding of risks [15], interests, and interactive features. Based on the project risk evaluation of the existing research results and references to related theory of behavioral economics, this paper expands evaluative dimensions and considers the main loss of psychological factors; it decomposes the overall value loss into objective value loss (cash flow) and subjective value loss (psychological utility). The subjective utility evaluation should not only fully consider main heterogeneity risk preference but also reflect the value preference and behavior game analysis of other related subject interactive factors into project risk evaluation parameters through scene investigation methods. Constructing utility function and "multidimensional interaction combination evaluation model" of large-scale infrastructure project risk on the basis of value preference and behavior game analysis contributes to making the project risk evaluation more scientific and reasonable.

\section{Analysis on Heterogeneous Belief and Behavior Game of Large-Scale Infrastructure Projects Subject Risk Discriminant}

Multiagents have different risk value preference and risk avoidance motivation. Their risks depend on and conflict with each other. Complex dynamic games existed between different bodies in promoting process. Body belief and behavior strategy interaction will have pivotal effect on the project risk assessment.

2.1. Analysis on Heterogeneous Preference of Large-Scale Infrastructure Projects Relevant Bodies in Risk Discriminant. Relevant bodies of large-scale infrastructure projects are

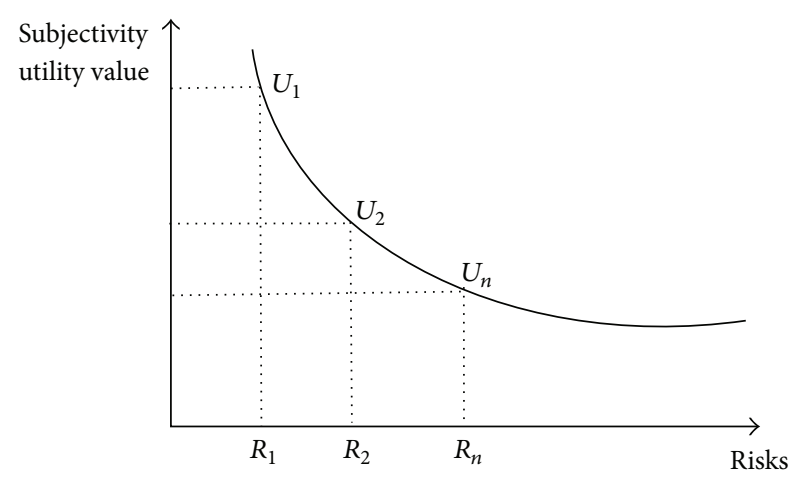

FIGURE 1: Risk utility curve of large-scale infrastructure project.

government, contractor (builder), designer, supervisor, suppliers, relocation households, and social public. They have heterogeneous risk value preference [14], different interest motives, and big differences on the importance of various risk judgments. For example, contractor mainly focuses on various economic and quality risks. Government gives more consideration to risks on social stability, public safety, and environmental ecology for it pays little attention to economic benefits. Designer and supervisor are concerned more with quality and technology risk that correspond to their responsibility. What relocation households consider the most is the risk of benefit loss in demolition, while social public is sensitive regarding environmental and ecological risk that existed in construction and operation.

All bodies' risk value preference can be ranked by risk utility value. Let us assume that body A ranks the importance of different project risks as $U_{1}>U_{2}>\cdots>U_{n}$, as is shown in Figure 1; it shows that $R_{1}$ have the maximum utility to body A, or body $\mathrm{A}$ is most sensitive to $R_{1}$. Different bodies, therefore, have different evaluations on the same risks. We must first find out the main body and then analyze the features of risk preference.

2.2. Relevant Body Evaluation and Behavioral Game of LargeScale Infrastructure Projects. As mentioned, main body has different sensitivity and pays attention to various project risks [15]. Risks of main body may conflict with other risks because the reduction of their own risk may increase the risk of others. But sometimes they are interdependent, because any "excessive self-interest behavior" will increase risks of other related subjects, causing noncooperation and eventually increasing risks. The mutual-interdependence and strategic interaction features will affect utility evaluation and corresponding risk avoidance behavior of each subject. Rational project subjects should not only evaluate negative effects brought to them but also evaluate negative effects brought to other associated subjects and then find an appropriate balance [16, 17].

Behavior game of large-scale infrastructure projects relevant bodies mainly happens between government and relocation households, government and contractor, and designer and supervisor; the details are shown in Figure 2. Firstly, as for game between government and relocation households, there are two strategy choices (positive response, disregard) 


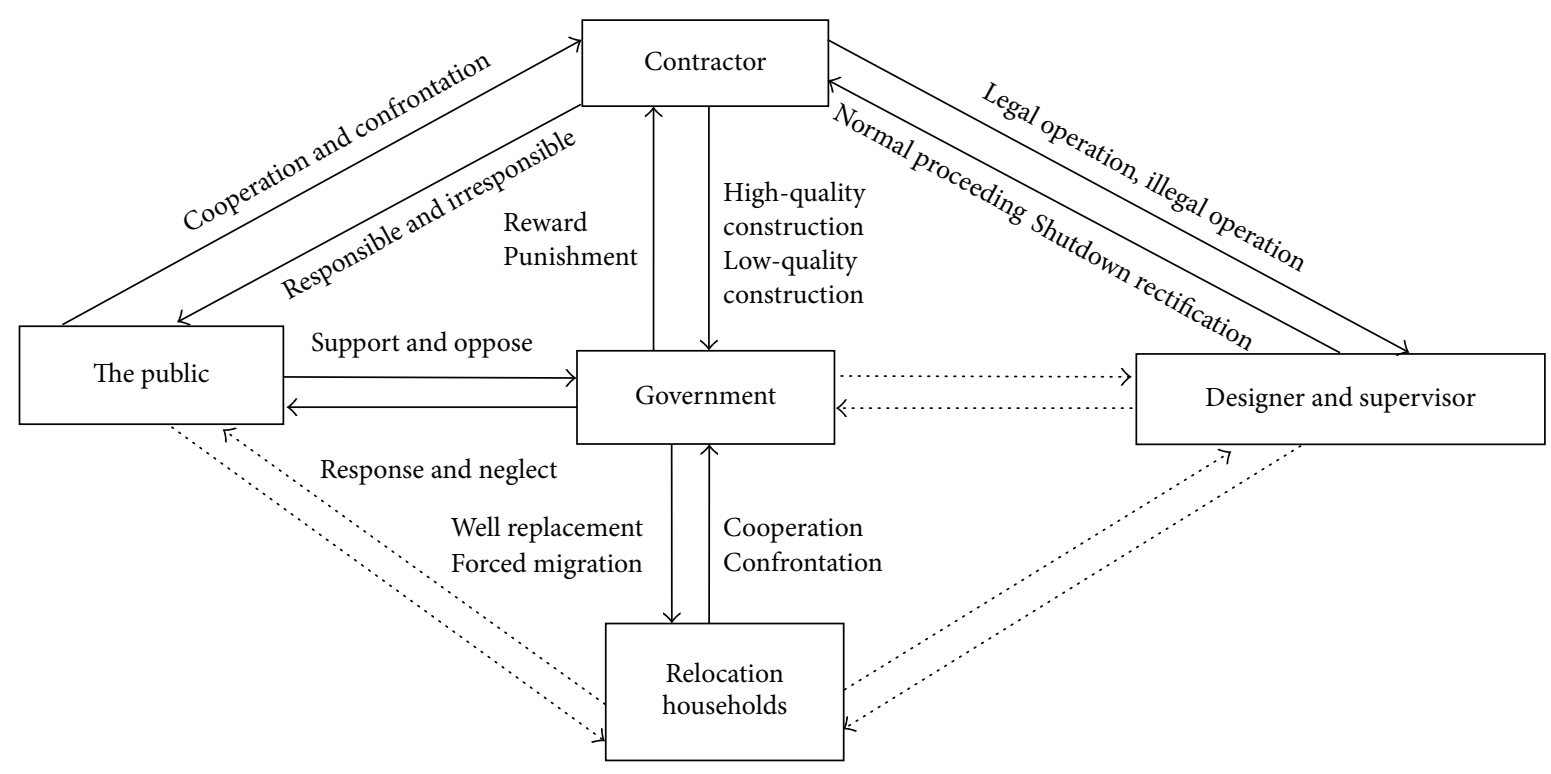

FIGURE 2: Associated subject's risk avoidance behavior game model.

for demolition and resettlement risk as well as environmental ecology risk; the relocated people and the public will support project construction; otherwise, the social stability risk that government is concerned with will increase. Secondly, as for game between government and contractor, the contractor has two strategy choices (high-quality construction, lowquality construction); if choosing high-quality construction, public safety risk concerned by government will be less and vice versa. There are also two corresponding strategies for government (payment on time, undue payment); if government chooses to pay on time, the economic risk will be reduced, and if government does not pay on time, the risk will rise. Thirdly, as for game between designer and supervisor, the contractor has two strategy choices (standard construction, nonstandard construction); if choosing standard construction, then technical and quality risk borne by designer and supervisor will be small and vice versa. Designer and supervisor also have two strategies (normal construction, shutdown and rectification); if they choose normal construction, the duration risk will be small and vice versa. Therefore, self-interest behavior of main bodies needs to meet the consistency demand with self-interest behavior of other associated subjects.

\section{Multidimensional and Interactive Assessment Model of Large-Scale Infrastructure Project}

The main feature of multidimensional and interactive assessment model of large-scale infrastructure project is "multidimensional utility analysis + interactive evaluation thinking + combination balanced calculation." The general idea is to build risk utility function based on features of the risk and analysis of evaluation dimension and then design individual risk, classified risk, and calculation formula of overall risk utility, respectively.

3.1. Multidimension of Risk Assessment of Large-Scale Infrastructure Project. Multiple features of project risks, such as objectivity, subjectivity, and gaming, determine the multidimension assessment [18]. Objectivity refers to occurrence probability and objective consequences of the risks that are free from main body. Subjectivity means different subjects having different feelings and evaluation on the same risks. Gaming means that the formation and evolution of risks are greatly influenced by game factors of multiple subjects. Risk utility assessment, therefore, should not only consider probability occurrences of risks and the objective losses but also consider multiple psychological disutility brought by main body, which includes body's own psychological disutility, the psychological disutility of other associated bodies, and the mutual-behavioral strategic interaction factors. The main assessment dimensions are shown in Figure 3.

3.2. Risk Assessment's Conceptual Model of Large-Scale Infrastructure Project. The conceptual model of large-scale infrastructure project is shown in Figure 4 on the basis of dimensional risk assessment.

3.3. Utility Function of Large-Scale Infrastructure Project. According to the above conceptual model, the utility function of large-scale infrastructure project is the sum of objective utility $\left(\mathrm{OU}_{r}\right)$ and subjective utility $\left(\mathrm{SU}_{r}\right)$. Total utility is equal to the sum of the objective and subjective utility. Objective utility is equal to the sum of the economic, social, and environmental ecological value loss brought by the project risk. The calculation of subjective utility is based on objective 


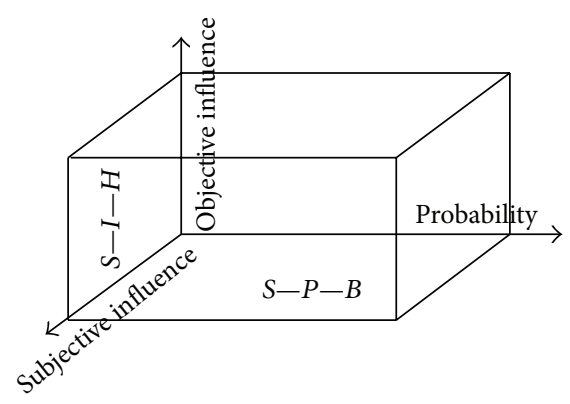

FIGURE 3: Multidimension of risk assessment of large-scale infrastructure project.

utility, which is divided into two parts: one is the psychological risk losses caused by negative effects; the second is psychological negative utility caused by caring for the other stakeholders' losses. Referring to relevant literature [19-21], the binomial utility function of building an individual risk under a single evaluation subject is as follows:

$$
\begin{aligned}
\mathrm{TU}_{r}= & \mathrm{OU}_{r}+\mathrm{SU}_{r}, \\
= & \mathrm{OU}_{r}+\beta \cdot \mathrm{OU}_{r}, \\
= & \mathrm{OU}_{r}(1+\beta), \\
= & \mathrm{OU}_{r} \times F_{r}(v, a, b), \\
= & P_{r} \times \Delta \mathrm{NPV}_{r} \times F_{r}(v, a, b), \\
= & P_{r} \\
& \times\left(w_{1} \cdot \Delta \mathrm{NPV}_{1}+w_{2} \cdot \Delta \mathrm{NPV}_{2}+w_{3} \cdot \Delta \mathrm{NPV}_{3}\right) \\
& \times\left[1+a \cdot f_{r}(a)+(1-a) \cdot f_{r}(b)\right] .
\end{aligned}
$$

$\mathrm{TU}_{r}$ is the total utility of project risk, $\mathrm{OU}_{r}$ is the objective utility of project risk, $\mathrm{SU}_{r}$ is the subjective utility of project risk, $\beta$ is the subjective utility coefficient of project risk, $0<$ $\beta<1, F_{r}(v, a, b)$ is the total utility coefficient of project risk to adjust based on objective utility, $P_{r}$ is the occurrence rate of project risk, $\triangle \mathrm{NPV}_{r}$ is the influence of project risk to overall value, $\triangle \mathrm{NPV}_{1}, \triangle \mathrm{NPV}_{2}$, and $\triangle \mathrm{NPV}_{3}$ are economic, social, and environmental ecology value losses brought by project risk, $w_{1}, w_{2}$, and $w_{3}$ are weightiness of three project values to overall value, $f_{r}(a)$ is the psychological disutility coefficient brought by body's own risk losses, $f_{r}(b)$ is the psychological disutility coefficient brought by body's sympathy and care to others' risk losses, $1-a$ is the altruistic preference coefficient, $a \cdot f_{r}(a)+(1-a) \cdot f_{r}(b)$ is the subjective utility coefficient of risks, and $1+a \cdot f_{r}(a)+(1-a) \cdot f_{r}(b)$ is the total utility coefficient of risks.

\subsection{The Formula of Risk Utility Combination}

3.4.1. Classified Risk Combination of Large-Scale Infrastructure Project. The individual risk's feature combination of largescale infrastructure project can be grouped as classified risk, such as technical risk, natural risk, management risk, economic risk, social risk, and legal risk. Individual risk
TABLE 1: Rating scale of risk occurrence probability.

\begin{tabular}{lc}
\hline $\begin{array}{l}\text { Qualitative description of risk } \\
\text { occurrence probability }\end{array}$ & $\begin{array}{c}\text { Quantitative description of risk } \\
\text { occurrence probability }\end{array}$ \\
\hline High possibility & $80-100 \%$ \\
Great possibility & $60-80 \%$ \\
Certain probability & $40-60 \%$ \\
Slim probability & $20-40 \%$ \\
Little probability & $0-20 \%$ \\
\hline
\end{tabular}

utility can be merged as total utility of classified risk with combination weighting method $[22,23]$; for example,

$$
\begin{aligned}
\mathrm{RU}_{k} & =\sum_{i=1}^{n} w_{i} \cdot \mathrm{TU}_{r i}, \\
& =\left(w_{1}, w_{2}, \ldots, w_{n}\right) \cdot\left[\begin{array}{cccc}
r_{11} & r_{12} & \cdots & r_{1 n} \\
r_{21} & r_{22} & \cdots & r_{2 m} \\
\cdots & \cdots & \cdots & \cdots \\
r_{m 1} & r_{m 2} & \cdots & r_{m n}
\end{array}\right],
\end{aligned}
$$

among which $w_{1}+w_{2}+w_{3}+\cdots+w_{n}=1$.

3.4.2. The Overall Risk Utility Combination of Large-Scale Infrastructure Project. The total utility of the overall risk can be calculated by combination weighting method on the basis of the above classified risk utility, as follows:

$$
\mathrm{WU}_{r l}=\sum_{l=1}^{x} w_{l} \cdot \sum_{i=1}^{n} w_{i} \cdot \mathrm{TU}_{r i},
$$

among which $w_{1}+w_{2}+w_{3}+\cdots+w_{l}=1$.

\section{Determination Method of Risk Utility Parameter of Large-Scale Infrastructure Project}

The main parameters of multidimensional and interactive assessment model of large-scale infrastructure project include risk probability, influence of the risk to the objective value, and psychological disutility of the risk to the body, which can be determined by ways of fuzzy evaluation, mathematical statistics, and scene investigation, respectively.

4.1. Interval Intuitionistic Fuzzy Evaluation of Risk Occurrence Probability. Risk probability can be estimated by interval intuitionistic fuzzy evaluation [24-26]. Namely, the range from $0 \%$ to $20 \%$ means little probability, $20 \%$ to $40 \%$ means slim probability, $40 \%$ to $60 \%$ means certain probability, $60 \%$ to $80 \%$ means great possibility, and $80 \%$ to $100 \%$ means high possibility. The probability grades are shown in Table 1.

4.2. Mathematical Statistics Evaluation of Project Risk to Overall Value Impact. Firstly, we should convert the overall value (sum of economic value, social value, and environmental 


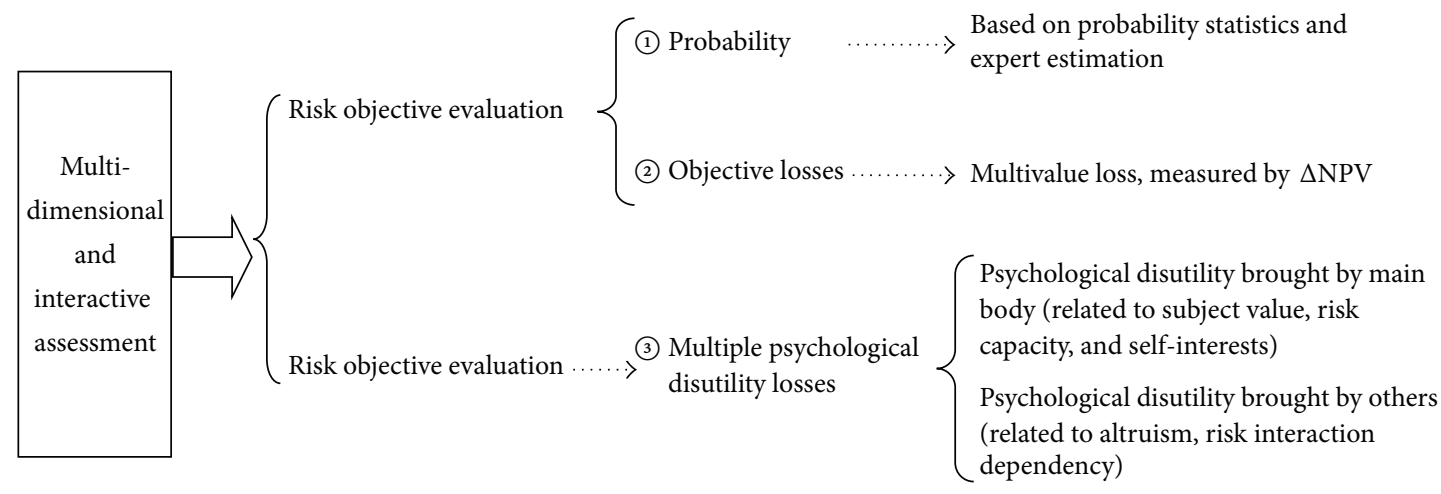

FIGURE 4: Multidimensional and interactive assessment conceptual model of large-scale infrastructure project.

TABLE 2: Impact analysis of CPI changes to NPV.

\begin{tabular}{lc}
\hline CPI & NPV more or less than expected (\%) \\
\hline $2 \%$ & +4.79 \\
$3 \%$ & +1.47 \\
$3.5 \%$ (assumed to current & Expectant NPV \\
CPI) & -1.36 \\
$4 \%$ & -2.34 \\
$5 \%$ & -5.67 \\
$6 \%$ & \\
\hline
\end{tabular}

and ecological value) to cash flow and then expect future CPI (Consumer Price Index) according to each project risk's impact on the overall value of historical statistical data; for example, given that the past CPI changes' impacts on overall value are shown in Table 2 and expecting the future CPI may be $5 \%$, then the CPI rising risk will have $2.34 \%$ of impact on the overall value: $\triangle \mathrm{NPV}_{r}=-2.34 \% \times \mathrm{NPV}$.

4.3. Scene Investigation Evaluation of Subjective Utility of Large-Scale Infrastructure Project. As mentioned earlier, subjective utility is the sum of psychological disutilities caused by main body's own losses and sympathy for others' losses. Scene investigation method is used to evaluate project risk's subjective utility.

4.3.1. Psychological Disutility Evaluation of Body's Self-Interest Motivation. Psychological utility value means the importance, tolerance, and psychological pain of risk loss to body itself. It is not only determined by the size of project risk but also related to the risk values, tolerance, and specific situation. We can divide psychological utility value into five grades in line with severity by using fuzzy evaluation method with fuzzy evaluation numbers $0,0.2,0.4,0.6$, and 0.8 . According to Rabin's (1993) equity theory and the ultimatum game experiments of Binmore K (2002), rational behavior subject generally allocates $60 \%$ of the earnings to itself and $40 \%$ to others, so it gains the maximum total utility. Therefore, the self-interest motivation factor is 0.6 and altruistic motives coefficient is 0.4 . Based on the above comprehensive analysis, the psychological utility loss value $\mathrm{SU}_{a}=\alpha \cdot f(a) \cdot \mathrm{OU}$; specific calculation results are shown in Table 3.

4.3.2. Psychological Disutility Evaluation of Body's Altruistic Motivation. Psychological disutility caused by sympathy for the other stakeholders' losses is measured by scene investigation method. The care degree of main body to other associated bodies has three degrees with coefficient of $0,0.3$, and 0.6 , respectively; respondents (i.e., the risk evaluation body) are required to choose one from three options "care deeply and sad," "care and sad," and "do not care and not sad" in the questionnaire and then calculate altruism utility coefficient $f(b)$ according to frequencies of three options; details are as follows:

$$
\begin{aligned}
f(b)= & \frac{m_{1}}{m_{1}+m_{2}+m_{3}} \times 0+\frac{m_{2}}{m_{1}+m_{2}+m_{3}} \times 0.3 \\
& +\frac{m_{3}}{m_{1}+m_{2}+m_{3}} \times 0.6,
\end{aligned}
$$

among which $m_{1}, m_{2}$, and $m_{3}$ are numbers of times of three options, respectively. Therefor, psychological disutility is $\mathrm{SU}_{b}=(1-\alpha) \cdot f(b) \cdot \mathrm{OU}$, among which subject altruistic motivation is $1-\alpha=0.4$; the specific calculation results are shown in Table 4.

4.4. Composite Weighting Method of Project Risk Utility Combination Computing. The risk index weight calculation adopts composite method of entropy method [26] (objectively) and analytic hierarchy process (AHP) method [27] (subjectively). This combinational method not only reflects the risk value preference of main body in the weight design but also eliminates the influence of artificial factors as much as possible.

4.4.1. The Entropy Method. The entropy method is an objective weight method with the feature of objectivity. It needs more project risk original data, and the specific steps are as follows.

Step 1. Construct historical data of $m$ item risk index at $n$ time points into judgment matrix $R R=\left(r_{i j}\right) n \times m(i=$ $1,2, \ldots, n ; j=1,2, \ldots, m)$. 
TABLE 3: Psychological disutility evaluation of body's self-interest motive.

\begin{tabular}{lcc}
\hline $\begin{array}{l}\text { Qualitative description of } \\
\text { body's self-interest motive psychological disutility }\end{array}$ & $\begin{array}{c}\text { Self-loss psychological coefficient } \\
f(a)\end{array}$ & $\begin{array}{c}\text { Self-interest psychological } \\
\text { utility value SU }_{a}\end{array}$ \\
\hline $\mathrm{Q}_{1}:$ deep psychological trauma, unbearable & 0.8 & $0.6 \times 0.8 \times \mathrm{OU}=0.48 \mathrm{OU}$ \\
$\mathrm{Q}_{2}:$ severe psychological trauma, bearable & 0.6 & $0.6 \times 0.6 \times \mathrm{OU}=0.36 \mathrm{OU}$ \\
$\mathrm{Q}_{3}:$ common psychological trauma, bearable & 0.4 & $0.6 \times 0.4 \times \mathrm{OU}=0.24 \mathrm{OU}$ \\
$\mathrm{Q}_{4}:$ slight psychological trauma, bearable & 0.2 & $0.6 \times 0.2 \times \mathrm{OU}=0.12 \mathrm{OU}$ \\
$\mathrm{Q}_{5}:$ negligible psychological trauma, completely & 0 & 0 \\
bearable & 0
\end{tabular}

TABLE 4: Psychological disutility evaluation of body's altruistic motivation.

\begin{tabular}{lcc}
\hline $\begin{array}{l}\text { Qualitative description of psychological } \\
\text { disutility caused by body's own risk loss }\end{array}$ & Utility coefficient $f(a)$ & $\begin{array}{c}\text { Altruistic psychological } \\
\text { utility value SU }\end{array}$ \\
\hline $\mathrm{T}_{1}$ : care deeply and sad & 0.6 & $0.4 \times 0.6 \times \mathrm{OU}=0.24 \mathrm{OU}$ \\
$\mathrm{T}_{2}$ : care and sad & 0.3 & $0.4 \times 0.3 \times \mathrm{OU}=0.12 \mathrm{OU}$ \\
$\mathrm{T}_{3}$ : do not care and not sad & 0 & 0 \\
\hline
\end{tabular}

Form original data matrix $R=\left(r_{i j}\right) n \times m$ :

$$
R=\left\{\begin{array}{llll}
r_{11} & r_{12} & \cdots & r_{1 m} \\
r_{21} & r_{22} & \cdots & r_{2 m} \\
\cdots & \cdots & \cdots & \cdots \\
r_{n 1} & r_{m 2} & \cdots & r_{n m}
\end{array}\right\}
$$

Step 2. To change data of judgment matrix $R$ by normalization processing into standardized matrix $U$, standardization method is as follows:

$$
u_{i j}=\frac{r_{i j}-r_{\min }}{r_{\max }-r_{\min }} .
$$

Step 3. Calculate all state probability and construct probability matrix $P_{i j}$ :

$$
P_{i j}=\frac{u_{i j}}{\sum_{j=1}^{m} u_{i j}} .
$$

Clearly, when $P_{i j}=0, \ln P_{i j}$ is meaningless; then, it can be amended as $P_{i j}=-\left(\left(1+u_{i j}\right) / \sum_{j=1}^{m}\left(1+u_{i j}\right)\right)$.

Step 4. Calculate all evaluation entropy index as follows:

$$
H_{i j}=-\frac{P_{i j} \ln P_{i j}}{\ln n} .
$$

Step 5. The entropy $i$ of evaluation index is as follows:

$$
W_{i}^{(1)}=\left(w_{i}\right)_{1 \times n}=\left\{\frac{1-H_{i}}{n-\sum_{i=1}^{n} H_{i}}\right\}_{1 \times n} .
$$

4.4.2. The AHP Method. The AHP method is a subjective weight method with the feature of subjectivity. It can comprehensively reflect opinions of various associated bodies for the selection of evaluation experts is extracted from various associated bodies; specific steps are as follows.
Step 1. Construct scale of risk factors for importance comparison.

Step 2. Construct two-two comparison matrix:

$$
A=\left[\begin{array}{ccccc}
1 & a_{12} & a_{13} & \cdots & a_{1 n} \\
a_{21} & 1 & a_{23} & \cdots & a_{2 n} \\
a_{31} & a_{32} & 1 & \cdots & a_{3 n} \\
\vdots & \vdots & \vdots & 1 & \vdots \\
a_{n 1} & a_{n 2} & a_{n 3} & \cdots & 1
\end{array}\right] .
$$

Step 3. Calculate weight vector:

$$
W_{i}^{(2)}=\left(w_{1}, w_{2}, w_{3}, \ldots, w_{i}\right)
$$

Step 4 (consistency check). Consider CI $=\lambda-n / n-1: \lambda$ means the maximum eigenvalue, $n$ means the number of risk factors, and if $\mathrm{CR}<0.1$, it means the judgment matrix is conformed to consistency check; otherwise, it would not be satisfied consistency.

The final result can be obtained by weighted calculation method based on $W_{i}^{(1)}$ and $W_{i}^{(2)}, W_{i}=\gamma W_{i}^{(1)}+(1-\gamma) W_{i}^{(2)}$, $0 \leq \lambda \leq 1$, and the size of $\gamma$ reflects the preference degree of subjective weight and objective weight.

\section{The Example Application and Result Analysis}

In order to verify the rationality and validity of risk assessment model put forward by Sections 3.2 and 3.3, example A of a key water conservancy project in Guangdong province is studied. Basic information is as follows: with a total investment of 1.5191948 billion yuan and two years and eight months of construction period, the aim is to promote shipping and improve the water environment, power generation, irrigation, water supply, aquaculture and tourism, 
TABLE 5: Scaling method to judge the importance of risk factor $a_{i j}$.

\begin{tabular}{lc}
\hline Scale & Meaning \\
\hline 1 & Two factors are equally important \\
3 & One factor is slightly more important than the other \\
7 & One factor is obviously more important than the other \\
9 & One factor is highly more important than the other \\
$2,4,6,8$ & One factor is extremely more important than the other \\
Reciprocal & Midvalue of the above two adjacent judgments \\
\hline
\end{tabular}

and so forth. The project includes hub on mainstream of Beijiang River and floodgate on tributary of Dayan River. The main buildings and equipment include earth dam, floodgate, overflow dam, draining sand buildings, factories, switching station, and mechanical and electrical equipment. Firstly, the questionnaire investigation method is used to the whole process of risk identification and then uses the above evaluation model to do interactive combination evaluation on the project risk utility.

5.1. Investigation and Identification of Project A on Key Risk Factors. We use numbers to show the severity of risks: "1" represents serious risks, "2" represents less serious risks, and " 3 " represents generally serious risks. We gave out 100 questionnaires to investigate [28] on participants of Project A such as governments, contractors, designers, and supervisors. We set the degree as " 1 " if more than 80 questionnaires' answers consider the risk as "serious" and " 2 " when 60 80 questionnaires' answers are "serious"; accordingly, we set the degree as " 3 " when we get $40-60$ questionnaires whose answers are "serious," but if we collect less than 40 copies whose answers are "serious," we will exclude the result from Table 6. We can conclude that main project risk factors of Project A in the whole life cycle are shown in Table 6.

5.2. The Design of the Risk Evaluation Index System of Project $A$. Based on the above research on ways of project risk classification, we classify the project risk according to the nature of the project risk [29], which are shown in Table 7.

5.3. The Calculation of Project A's Individual Risk (Secondary Risk) Utility Value. According to financial evaluation and national economic evaluation report, the overall net present value (NPV) of Project A (sum of economic value, social value, and environmental and ecological value) is about 20 billion yuan. Then, the objective utility value of the individual risk can be calculated according to risk probability analysis method and sensitivity analysis method proposed in Sections 4.1 and 4.2, respectively; total utility is equal to objective utility value multiplied by the total utility coefficient; it reflects the selfish and altruistic motives of multiple project related subject as well as the psychological game equilibrium between each other; details are shown in Table 8 .

As we can see from Table 8, market demand reduction is the most possible occurrence risk with a probability of $93 \%$. We can learn from Table 5 that decision-making mistake has the largest influence on objective value with a sensitivity coefficient of 0.29 , while the biggest psychological utility coefficient risk is the main body default with an associated value of 0.58 , showing that it is the most sensitive, most unwilling or unbearable risk of main body.

5.4. The Calculation of Project A's Classification and Overall Risk Combination Utility. Firstly, we should get the individual risk index weights of Project A by the combination of the AHP method and the entropy method. Then, the individual risk utility multiplied by and added to their respective weight is the total utility of risk classification. Finally, we can calculate the total utility of overall risk by the same method. The calculation process is omitted and the results are shown in Table 9.

5.5. Results Analysis and Policy Suggestion. From the calculation results of Table 9, we can conclude the following: (1) As shown in Table 2, the utility loss sort caused by risk classification is as follows: management risk $>$ technology risk $>$ natural risk $>$ social risk $>$ legal risk $>$ and economic risk, showing that management risk has caused the most biggest utility loss and technology risk takes the second place. These two kinds of risks need to be monitored for they have strong controllability and are greatly influenced by human factors. (2) Economic risk and legal risk cause little utility, meaning that the influence of macroenvironment is not so big, and main body violation is also unlikely to happen. (3) The overall risk evaluation value of Project A is -2.169 billion RMB with a negative deviation of $10.84 \%$ relative to 20 billion yuan of the overall project expected value, showing that supervision measures should be strengthened to guard against and dissolve the risk. (4) The classification risk and overall risk are not a simple addition of each individual risk but through the addition of combination weighting methods. (5) The calculation result above is risk evaluation in specific point. But it is not static, and it will constantly evolve with the change of time, the main body belief, and internal and external environment. Therefore, dynamic tracking evaluation is needed.

\section{Conclusions}

Through game theory and mathematical statistics analysis method, this paper focuses on value losses brought by 


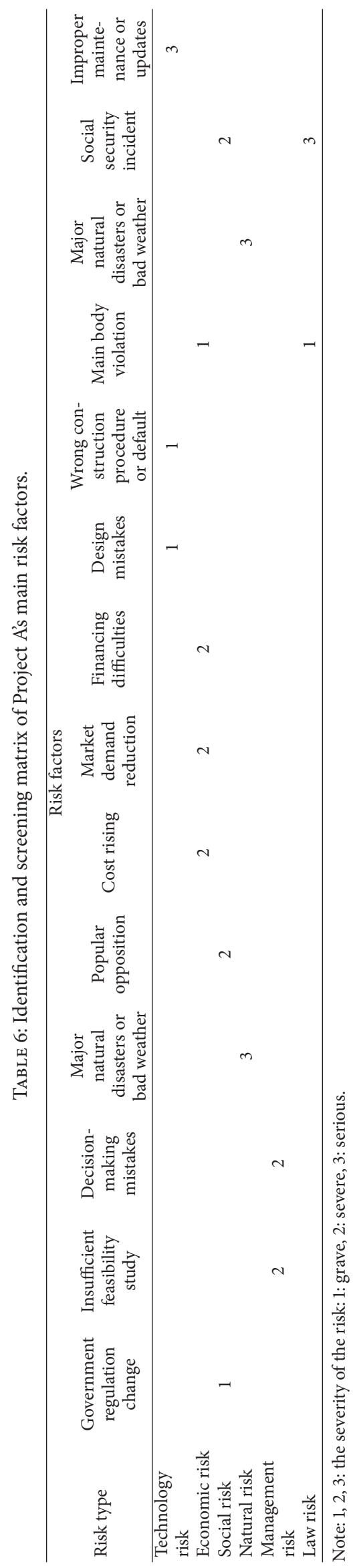


TABLE 7: Risk evaluation index system of Project A.

\begin{tabular}{|c|c|c|}
\hline Destination layer & Primary risk & Secondary risk \\
\hline \multirow{12}{*}{ The overall risk (portfolio risk) } & \multirow{3}{*}{ Technology risk (TR) } & Design mistakes $\left(\mathrm{R}_{11}\right)$ \\
\hline & & Wrong construction procedure $\left(\mathrm{R}_{12}\right)$ \\
\hline & & Improper maintenance or updates $\left(R_{13}\right)$ \\
\hline & \multirow{3}{*}{ Economic risk (ER) } & Cost rising $\left(\mathrm{R}_{21}\right)$ \\
\hline & & Market demand reduction $\left(\mathrm{R}_{22}\right)$ \\
\hline & & Financing difficulties $\left(\mathrm{R}_{23}\right)$ \\
\hline & \multirow{3}{*}{ Social risk (SR) } & Government regulation change $\left(\mathrm{R}_{31}\right)$ \\
\hline & & Popular opposition $\left(\mathrm{R}_{32}\right)$ \\
\hline & & Social security incident $\left(\mathrm{R}_{33}\right)$ \\
\hline & Natural risk (NR) & $\begin{array}{c}\text { Major natural disasters }\left(\mathrm{R}_{41}\right) \\
\text { Bad weather }\left(\mathrm{R}_{42}\right)\end{array}$ \\
\hline & Management risk (MR) & $\begin{array}{l}\text { Insufficient feasibility study }\left(\mathrm{R}_{51}\right) \\
\text { Decision-making mistakes }\left(\mathrm{R}_{52}\right)\end{array}$ \\
\hline & Law risk (LR) & $\begin{array}{l}\text { Main body violation }\left(\mathrm{R}_{61}\right) \\
\text { Main body default }\left(\mathrm{R}_{62}\right)\end{array}$ \\
\hline
\end{tabular}

TABLE 8: The calculation of Project A's individual risk utility value.

\begin{tabular}{|c|c|c|c|c|c|c|c|}
\hline Individual risks & $\begin{array}{l}\text { Occurrence } \\
\text { probability }\end{array}$ & $\begin{array}{c}\text { Influence on } \\
\text { objective value }\end{array}$ & $\begin{array}{c}\Delta \mathrm{NPV} \\
\text { (billion yuan) }\end{array}$ & $\begin{array}{c}\text { Objective } \\
\text { utility (billion } \\
\text { yuan) }\end{array}$ & $\begin{array}{l}\text { Subjective } \\
\text { utility } \\
\text { coefficient }\end{array}$ & $\begin{array}{l}\text { Total utility } \\
\text { coefficient }\end{array}$ & Total utility \\
\hline Design mistakes $\left(\mathrm{R}_{11}\right)$ & $38 \%$ & $-17 \%$ & -34 & -12.92 & 0.32 & 1.32 & -15.89 \\
\hline $\begin{array}{l}\text { Wrong construction } \\
\text { procedure }\left(\mathrm{R}_{12}\right)\end{array}$ & $29 \%$ & $-16 \%$ & -32 & -9.28 & 0.34 & 1.34 & -12.44 \\
\hline $\begin{array}{l}\text { Improper maintenance or } \\
\text { updates }\left(\mathrm{R}_{13}\right)\end{array}$ & $34 \%$ & $-12 \%$ & -24 & -8.16 & 0.23 & 1.23 & -10.77 \\
\hline Cost rising $\left(\mathrm{R}_{21}\right)$ & $78 \%$ & $-6 \%$ & -12 & -9.36 & 0.27 & 1.27 & -11.89 \\
\hline $\begin{array}{l}\text { Market demand reduction } \\
\left(\mathrm{R}_{22}\right)\end{array}$ & $93 \%$ & $-4 \%$ & -8 & -7.44 & 0.25 & 1.25 & -9.30 \\
\hline Financing difficulties $\left(\mathrm{R}_{23}\right)$ & $23 \%$ & $-13 \%$ & -26 & -5.98 & 0.31 & 1.31 & -7.83 \\
\hline $\begin{array}{l}\text { Government regulation } \\
\text { change }\left(\mathrm{R}_{31}\right)\end{array}$ & $48 \%$ & $-19 \%$ & -38 & -18.24 & 0.45 & 1.45 & -26.45 \\
\hline Popular opposition $\left(\mathrm{R}_{32}\right)$ & $68 \%$ & $-8 \%$ & -16 & -10.88 & 0.09 & 1.09 & -11.86 \\
\hline $\begin{array}{l}\text { Social security incident } \\
\left(\mathrm{R}_{33}\right)\end{array}$ & $26 \%$ & $-9 \%$ & -18 & -4.68 & 0.24 & 1.24 & -5.80 \\
\hline $\begin{array}{l}\text { Major natural disasters } \\
\left(\mathrm{R}_{41}\right)\end{array}$ & $56 \%$ & $-16 \%$ & -32 & -17.92 & 0.33 & 1.33 & -23.83 \\
\hline Bad weather $\left(\mathrm{R}_{42}\right)$ & $68 \%$ & $-2 \%$ & -4 & -2.72 & 0.11 & 1.11 & -3.02 \\
\hline $\begin{array}{l}\text { Insufficient feasibility study } \\
\left(\mathrm{R}_{51}\right)\end{array}$ & $44 \%$ & $-18 \%$ & -36 & -15.84 & 0.38 & 1.38 & -21.86 \\
\hline $\begin{array}{l}\text { Decision-making mistakes } \\
\left(\mathrm{R}_{52}\right)\end{array}$ & $36 \%$ & $-29 \%$ & -58 & -20.88 & 0.54 & 1.54 & -32.16 \\
\hline Main body violation $\left(\mathrm{R}_{61}\right)$ & $52 \%$ & $-8 \%$ & -16 & -8.32 & 0.49 & 1.49 & -12.40 \\
\hline Main body default $\left(\mathrm{R}_{62}\right)$ & $13 \%$ & $-12 \%$ & -24 & -3.12 & 0.58 & 1.58 & -4.93 \\
\hline
\end{tabular}

multidimensional interaction evaluation of large-scale infrastructure project from the angle of subject utility loss and builds the multidimensional interaction combination evaluation model and calculation analysis by specific examples; the main research conclusions are as follows:

(1) The overall value of large-scale infrastructure projects includes economic value, social value and environmental ecology value, and hence the sum of the objective project risk value losses. Of course, the social and environmental ecological value loss can be converted to the corresponding cash flow losses. We can measure the overall value of the project according to financial evaluation and national economic evaluation index and the influence on the value of the whole project by using historical data statistical analysis of risk factors.

(2) This paper enriches and expands risk evaluation dimensions on the basis of the existing project risk evaluation model; it fully considers not only project economic value, social value, and environmental and 
TABLE 9: The calculation of Project A's classification and overall risk combination utility.

\begin{tabular}{|c|c|c|c|c|c|c|}
\hline \multirow{2}{*}{ Destination layer } & \multicolumn{3}{|c|}{ System layer } & \multicolumn{3}{|l|}{ Index layer } \\
\hline & Classification risk index & Weight & Utility & Risk index & Weight & Utility \\
\hline \multirow{15}{*}{$\begin{array}{l}\text { The overall risk } \\
\text { utility of Project A } \\
\sum \mathrm{Wu}=-21.69\end{array}$} & \multirow{3}{*}{ Technology risk } & \multirow{3}{*}{0.12} & \multirow{3}{*}{-23.86} & Design mistakes $\left(\mathrm{R}_{11}\right)$ & 0.64 & -15.89 \\
\hline & & & & Wrong construction procedure $\left(\mathrm{R}_{12}\right)$ & 0.24 & -12.44 \\
\hline & & & & Improper maintenance or updates $\left(\mathrm{R}_{13}\right)$ & 0.12 & -10.77 \\
\hline & \multirow{3}{*}{ Economic risk } & \multirow{3}{*}{0.20} & \multirow{3}{*}{-10.44} & Cost rising $\left(\mathrm{R}_{21}\right)$ & 0.53 & -11.89 \\
\hline & & & & Market demand reduction $\left(\mathrm{R}_{22}\right)$ & 0.31 & -9.30 \\
\hline & & & & Financing difficulties $\left(\mathrm{R}_{23}\right)$ & 0.16 & -7.83 \\
\hline & \multirow{3}{*}{ Social risk } & \multirow{3}{*}{0.19} & \multirow{3}{*}{-19.51} & Government regulation change $\left(\mathrm{R}_{31}\right)$ & 0.57 & -26.45 \\
\hline & & & & Popular opposition $\left(\mathrm{R}_{32}\right)$ & 0.32 & -11.86 \\
\hline & & & & Social security incident $\left(\mathrm{R}_{33}\right)$ & 0.11 & -5.80 \\
\hline & \multirow{2}{*}{ Natural risk } & \multirow{2}{*}{0.08} & \multirow{2}{*}{-21.33} & Major natural disasters $\left(\mathrm{R}_{41}\right)$ & 0.88 & -23.83 \\
\hline & & & & Bad weather $\left(\mathrm{R}_{42}\right)$ & 0.12 & -3.02 \\
\hline & \multirow{2}{*}{ Management risk } & \multirow{2}{*}{0.32} & \multirow{2}{*}{-32.42} & Insufficient feasibility study $\left(\mathrm{R}_{51}\right)$ & 0.67 & -21.86 \\
\hline & & & & Decision-making mistakes $\left(\mathrm{R}_{52}\right)$ & 0.33 & -32.16 \\
\hline & \multirow{2}{*}{ Law risk } & \multirow{2}{*}{0.09} & \multirow{2}{*}{-10.53} & Main body violation $\left(\mathrm{R}_{61}\right)$ & 0.75 & -12.40 \\
\hline & & & & Main body default $\left(\mathrm{R}_{62}\right)$ & 0.25 & -4.93 \\
\hline
\end{tabular}

ecological value losses but also negative utility and subjective game evaluation factors, so as to make risk evaluation more in accord with the features of the project itself and balanced interests-oriented evaluation thoughts.

(3) The selection of main parameters is based on scene investigation and fuzzy evaluation, which can make the risk value of different plural subjects and game factors fully reflected in the project risk evaluation, making the measurement of the project risk more balanced and reasonable. But parts of the project risk parameters have certain intuitive fuzziness, which need to be verified by using behavior experiment methods in later study.

(4) The utility of project risk can be measured, the precise mathematical method is science, and fuzzy evaluation method is more suitable for the characteristics of the project risk. The selection and evaluation of main project risk parameters in this paper are based on the investigation and fuzzy evaluation of related subject, which can make different values and plural factors fully reflected in the project risk evaluation so as to make the project risk measure more balanced and reasonable.

The inadequacy of this paper is the fuzzy evaluation method used for several times, which leads to a certain gray level and nonprecision of some project risk parameters; thus, behavioral experiment method is needed in future studies for proof and correction.

\section{Competing Interests}

The authors declare that they have no competing interests.

\section{Acknowledgments}

This paper is funded by national social fund project of "Risk Control Mechanism and Strategy science Research of China's Major Overseas Infrastructure Investment Projects" of 2015, and NNSF of China (71171203), and Natural Science Foundation of Hunan Province (2015JJ2025).

\section{References}

[1] X. He and Y. Chen, "Utility function and doer: an interpretation from financial economics perspective," Finance Theory and Practice, no. 9, pp. 2-7, 2008.

[2] J. von Neumann and O. Morgenstern, Theory of Games and Economic Behavior, Princeton University Press, Princeton, NJ, USA, 1944.

[3] J. Zhang and D. Zhong, "Appraisal method study on multidimensional efficacy function of engineering project risk," Journal of Luoyang University, no. 2, pp. 48-53, 2002.

[4] S. Liu and L. Wang, "Understanding the impact of risks on performance in internal and outsourced information technology projects: the role of strategic importance," International Journal of Project Management, vol. 32, no. 8, pp. 1494-1510, 2014.

[5] S. Liu, "How the user liaison's understanding of development processes moderates the effects of user-related and project management risks on IT project performance," Information \& Management, vol. 53, no. 1, pp. 122-134, 2016.

[6] M. Xu, S. Zhang, and X. Wang, "The evolutionary algorithm on multiplayer games utility function," Pattern Recognition and Artificial Intelligence, no. 6, pp. 708-714, 2006.

[7] G. F. Loewenstein, E. U. Weber, C. K. Hsee, and N. Welch, "Risk as feelings," Psychological Bulletin, vol. 127, no. 2, pp. 267-286, 2001.

[8] P. Slovic, M. L. Finucane, E. Peters, and D. G. MacGregor, "Risk as analysis and risk as feelings: some thoughts about affect, reason, risk, and rationality," Risk Analysis, vol. 24, no. 2, pp. 311$322,2004$. 
[9] S. Lu and H. Yan, "A model for evaluating the applicability of partnering in construction," International Journal of Project Management, vol. 25, no. 2, pp. 164-170, 2007.

[10] L. Li, Z. Liu, and K. Zhang, "Participants status asymmetric game model under the condition of the PPP project risk allocation," Systems Engineering: Theory and Practice, no. 8, pp. 1940-1948, 2013.

[11] P. Xiang and T. Lu, "Engineering project risk generation mechanism," Building Economy, vol. 29, no. 9, pp. 43-45, 2011.

[12] L. Li, Z.-H. Liu, and K.-C. Zhang, "Participants status asymmetric game model under the condition of the PPP project risk allocation," System Engineering Theory and Practice, no. 8, pp. 1940-1948, 2013.

[13] W. Bi and X. Chen, "Group-decision-method research based on multiple attribute of target risk," Statistics \& Information Forum, no. 3, pp. 8-12, 2009.

[14] H. Bai, J. Guo, and X. Xi, “The experimental study of strategic investment decision effecting senior management team's risk preference heterogeneity," Nankai Business Review, no. 10, pp. 25-30, 2007.

[15] Y. Liu, X. Chen, and G. Lu, "The impact of the role of decision makers and the influence of related factors on risk appetite," Journal of Psychological Science, vol. 33, no. 3, pp. 548-551, 2010.

[16] G. Xu, Z. Jia, and X. Wang, "Economic analysis of economic man's altruistic behavior," The Economist, no. 1, pp. 10-17, 2008.

[17] H. Chen, "Theory basis and the latest development of economic man hypothesis on altruism and selfish consistency," Academic Monthly, no. 11, pp. 78-80, 2012.

[18] H. Thamhain, "Managing risks in complex projects," Project Management Journal, vol. 44, no. 2, pp. 20-35, 2013.

[19] X. Xu, Q. Song, and L. Ma, "The portfolio model and empirical study based on representative deviation behavior," System Engineering-Theory and Practice, no. 1, pp. 34-40, 2012.

[20] X. Jiang and Y. Li, "Breakwater decision-making model research of joint utility theory and risk quantification," Marine Science Bulletin, no. 1, pp. 65-74, 2009.

[21] C. Jiang, Q. Xu, and S. Zhang, "Higher-order moments and dynamic portfolio investment based on multi-objective optimization and utility theory," Statistical Research, no. 10, pp. 7379, 2009.

[22] L. Ma, Y. Li, L. Liang, M. Li, and L. Cheng, "A novel method of quantitative risk assessment based on grid difference of pipeline sections," Safety Science, vol. 59, pp. 219-226, 2013.

[23] Y. Gong and Y. Ping, "Application of multi-factor hierarchical fuzzy comprehensive evaluation model in risk assessment of gas exploration," China-USA Business Review, vol. 7, no. 5, pp. 5964, 2008.

[24] Z.-S. Xu and J. Chen, "An approach to group decision making based on interval-valued intuitionistic judgment matrices," System Engineering Theory and Practice, vol. 27, no. 4, pp. 126133, 2007.

[25] X. Zhang and G. Wei, "Risk group evaluation method of risk investment project based on intuitionistic fuzzy sets," Science and Technology Management Research, no. 7, pp. 448-450, 2009.

[26] Q. Cheng, "The structure entropy method of evaluation index weight determination," System Engineering Theory and Practice, no. 7, pp. 1225-1228, 2010.

[27] Z. Ruan, C. Li, and Z. Li, "Risk evaluation based on improved AHP of the underground mine inrush water," Journal of Industrial Safety and Environmental Protection, no. 3, pp. 47-50, 2016.
[28] X. Qin and L. Jin, “The assessment and analysis of risk factors on whole life cycle of green building: based on the exploration of questionnaire," http://www.paper.edu.cn.

[29] M. Baydoun, "Risk management of large-scale development projects in developing countries: cases from MDI's projects," International Journal of Technology Management \& Sustainable Development, vol. 9, no. 3, pp. 237-249, 2011. 


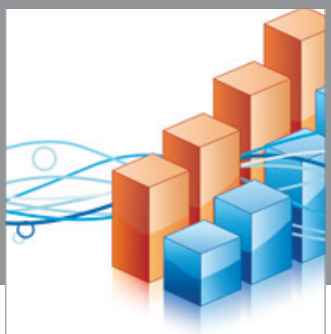

Advances in

Operations Research

vatem alat4

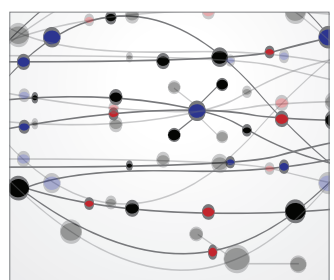

\section{The Scientific} World Journal
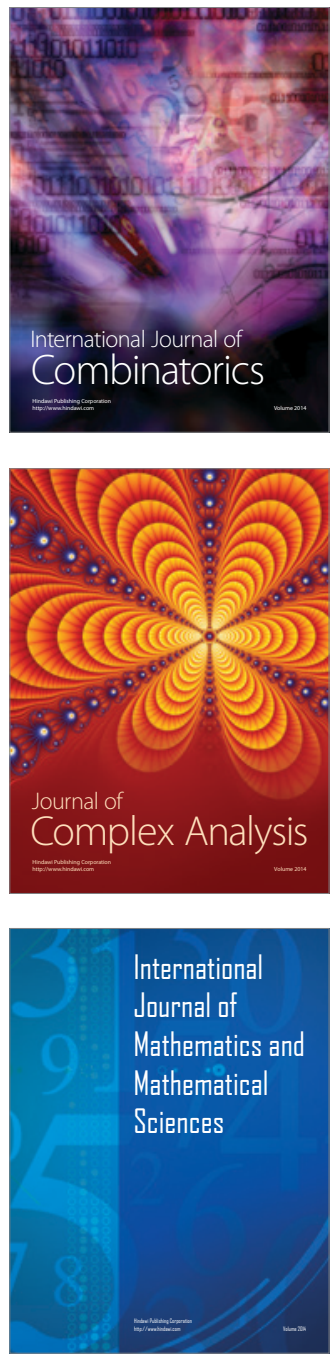
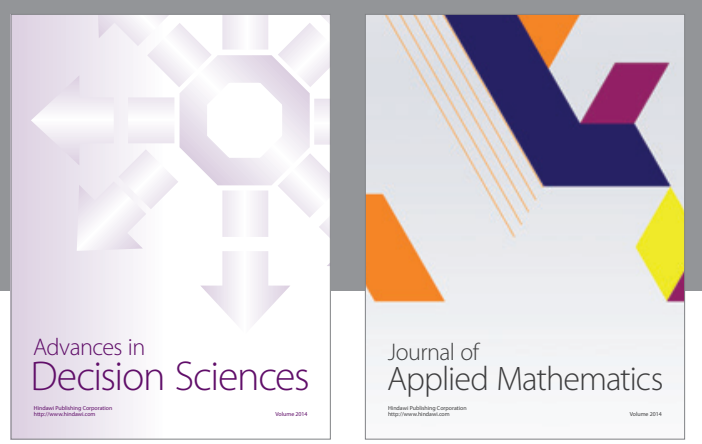

Algebra

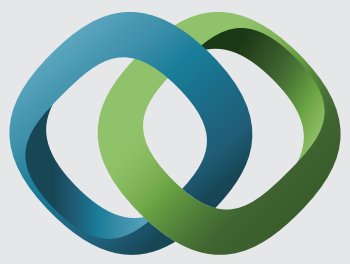

\section{Hindawi}

Submit your manuscripts at

http://www.hindawi.com
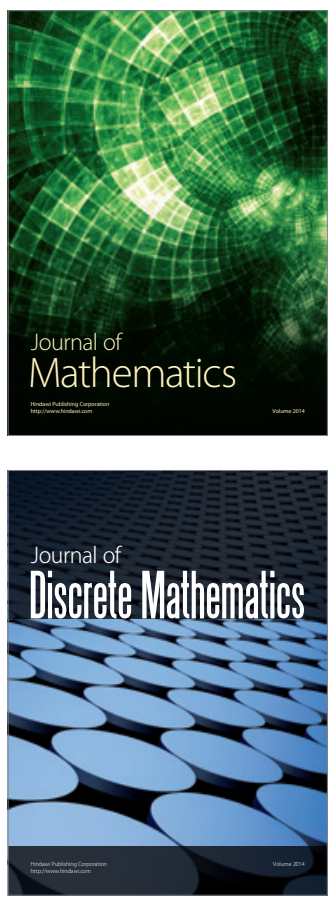

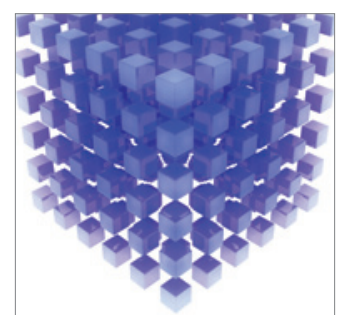

Mathematical Problems in Engineering
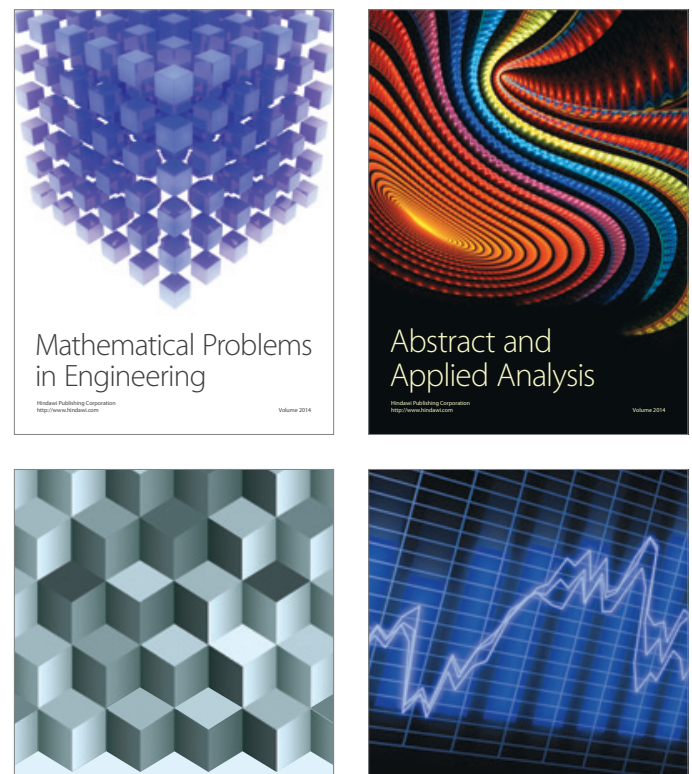

Journal of

Function Spaces

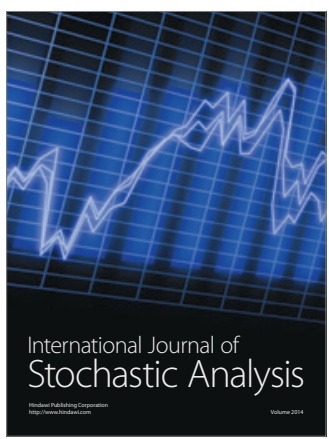

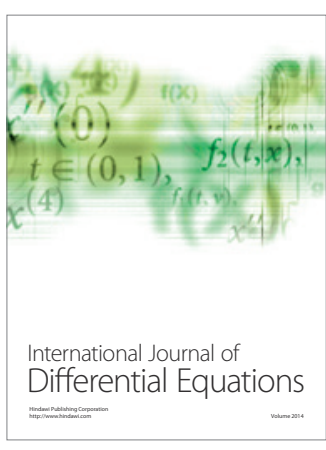
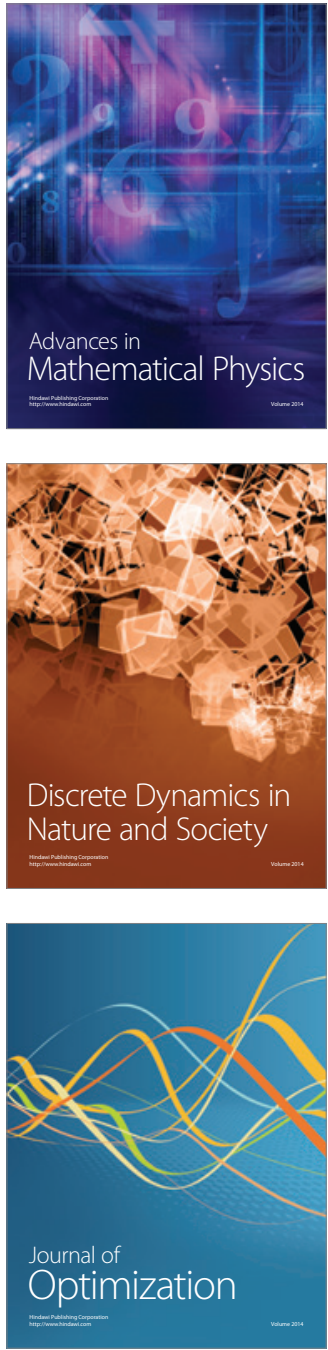